\title{
LA CONTINUIDAD DEL DISCURSO NEOCONSERVADOR FRENTE A LA POLÍTICA EXTERIOR DE LA ADMINISTRACIÓN OBAMA
}

\author{
Manuel Iglesias ${ }^{1}$ \\ Universidad Complutense de Madrid
}

\begin{abstract}
Resumen:
A lo largo del pasado sexenio, la doctrina neoconservadora se ha convertido en la voz más beligerante contra la política exterior de la Administración Obama. Este artículo se propone analizar el contenido de la crítica neoconservadora, una crítica radical, pues no se limita a un disenso menor en torno a determinadas áreas temáticas o regionales de la política exterior estadounidense, sino que se presenta como un rechazo frontal tanto a sus fundamentos teóricos como a su implementación práctica. De este modo, se verá que el neoconservadurismo continúa firmemente apegado a sus principios, con un discurso que mantiene como eje su particular concepción del excepcionalismo americano. El neoconservadurismo sigue defendiendo la validez de sus ideas centrales y se reivindica como la mejor doctrina de política exterior posible para los EE.UU., la única adecuada para evitar su declive internacional y mantener el ‘orden mundial americano' en las próximas décadas. Ello nos permitirá observar cómo, pese a su actual falta de influencia política, el mismo sigue gozando de una vitalidad que contradice las recurrentes afirmaciones sobre su desaparición.
\end{abstract}

Palabras clave: Neoconservadurismo, política exterior de los EE.UU., Barack Obama.

Title in English: "The Continuity of the Neoconservative Discourse against the Obama Administration's Foreign Policy"

\begin{abstract}
:
Over the last six years, the neoconservative doctrine has become the most belligerent voice against the Obama Administration's Foreign Policy. This article seeks to analyze the content of the neoconservative criticism-a radical one, because it is not limited to a minor dissent about a particular regional or thematic area of American Foreign Policy, but it is an outright rejection of its theoretical foundations and practical implementation. Thus it will be seen that neoconservatism remains firmly committed to its principles, with a discourse that is always based on its particular conception of American exceptionalism. Neoconservatism continues to defend the validity of its core ideas and vindicates itself as the best possible foreign policy doctrine for the US, the only one capable of avoiding its international decline and of preserving the world American Order in the decades to come. This will enable us to see how, despite its current lack of political influence, neoconservatism continues to enjoy a vitality that contradicts the recurring assertions about its demise.
\end{abstract}

Keywords: Neoconservatism, US Foreign Policy, Barack Obama.

Copyright $\odot$ UNISCI, 2015.

Las opiniones expresadas en estos artículos son propias de sus autores, y no reflejan necesariamente la opinion de UNISCI. The views expressed in these articles are those of the authors, and do not necessarily reflect the views of UNISCI.

\footnotetext{
${ }^{1}$ Manuel Iglesias Caviccchioli es Doctor e investigador en Relaciones Internacionales (UCM) y Miembro Colaborador de FLACSO-España.

Email: manuel.iglesias@cps.ucm.es.
} 


\section{Introducción: los neoconservadores y Barack Obama}

Desde que George W. Bush abandonara la Casa Blanca el 20 de enero de 2009, el neoconservadurismo no ha desaparecido del debate sobre la política exterior americana. Pese al descrédito generado por la guerra de Irak y a los duros ataques vertidos tanto desde el Partido Demócrata como desde el Partido Republicano, los neoconservadores han continuado defendiendo sus ideas y han ejercido una férrea crítica contra la política exterior de la Administración Obama.

Como veremos, esta crítica no se limita a discrepancias concretas sino que se dirige al núcleo de los principios básicos que han de regir la política exterior de los EE.UU., a la concepción de los EE.UU. y al propio papel que estos han de jugar en el mundo. Constituye, por ende, una verdadera enmienda a la totalidad. Así, por ejemplo, según John Bolton, Obama ha llevado a cabo una política exterior confusa que ha combinado las peores características del aislacionismo y el multilateralismo ${ }^{2}$, mientras que para Charles Krauthammer se trata de una política exterior carente de todo atisbo de pensamiento estratégico ${ }^{3}$.

Hay que señalar que algunos neoconservadores destacados como Joshua Muravchik han realizado en este periodo una cierta autocrítica en torno a la guerra de Irak que les ha llevado a admitir que librar aquella guerra fue un error castigado en las urnas por el pueblo americano ${ }^{4}$. No obstante, esta autocrítica no se ha visto acompañada por un replanteamiento de los principios fundamentales del neoconservadurismo como doctrina de política exterior de los EE.UU. Antes bien, Irak vendría a ser la excepción que confirma la regla del apabullante historial de aciertos neoconservadores en política exterior desde la era Reagan ${ }^{5}$.

En efecto, en estos años, aunque los postulados teóricos básicos del neoconservadurismo no han experimentado cambios significativos, el discurso neoconservador ha abordado temas relativamente novedosos en los que ha continuado defendiendo activamente sus ideas. Así, la oposición a la gobernanza global, como renovación de su conocido rechazo del multilateralismo, ha sido una cuestión que ha centrado los análisis de la doctrina neoconservadora en los últimos tiempos. Han vuelto, también, a la palestra temas típicos del neoconservadurismo como la polémica sobre el excepcionalismo americano como fuente de la política exterior y el debate sobre el declive de los EE.UU. En todo caso, comprobaremos que las diferencias que mantienen los neoconservadores con la política exterior del presidente Obama se han revelado a lo largo de este periodo, sea en el plano conceptual o en el práctico, como absolutamente irreconciliables.

\section{Obama y el excepcionalismo americano}

El excepcionalismo americano es una pieza clave en la visión del mundo neoconservadora. Se trata, sin duda, de una concepción teórica de indudable arraigo histórico en la cultura política americana sin la que no es posible entender la política exterior de los EE.UU. desde sus propios orígenes fundacionales ${ }^{6}$. Siguiendo a Lipset, hay que recordar que, en su sentido

\footnotetext{
${ }^{2}$ Bolton, John R.: "Doubling Down on a Muddled Foreign Policy", The Wall Street Journal, 28 de mayo de 2014.

${ }^{3}$ Krauthammer, Charles: "On Obama's foreign policy, Clinton got it right", The Washington Post, 14 de agosto de 2014.

${ }^{4}$ Muravchik, Joshua (2010a): "Neocon Wrongs and Rights", SAIS Review of International Affairs, vol. 30, $\mathrm{n}^{\mathbf{0}} 1$, (Invierno-primavera 2010), p. 11.

${ }^{5}$ Muy destacadamente, los neoconservadores consideran que la aplicación de sus ideas fue decisiva para que Reagan llevara a los EE.UU. a derrotar al comunismo y a salir victoriosos de la Guerra Fría: Ibid., p. 16.

${ }^{6}$ Este concepto fue introducido por Alexis de Tocqueville en su obra clásica La democracia en América al referirse a los EE.UU. como una nación excepcional y, como tal, incomparable con otras naciones democráticas.
} 
original, el excepcionalismo significa que los EE.UU. son un país único y diferente al resto de países del mundo pero no necesariamente un país superior a los demás ${ }^{7}$.

Los neoconservadores realizan una particular interpretación del excepcionalismo americano que, en primer lugar, implica una noción universalista del mismo centrada en los valores antes que en la geografía y, en tal sentido, considera que los EE.UU. son la primera y la única nación universal que existe en el mundo: una nación que tiene una misión especial a escala mundial que necesita cumplir para, así, desarrollar su identidad nacional plenamente. Asimismo, la interpretación neoconservadora del excepcionalismo se caracteriza y distingue por su firme creencia en la superioridad americana: los EE.UU. no sólo son un país único y diferente cualitativamente por sus orígenes nacionales basados en el rechazo al sistema europeo de Estados y por las particularidades propias de su sistema político, sino que son, además, una nación superior al resto de países del mundo ${ }^{8}$. Esta superioridad americana, tal como la entienden los neoconservadores, se sustenta en dos dimensiones complementarias: una dimensión basada en los principios morales y en los valores y otra sustentada en el poder militar.

En lo concerniente a la dimensión moral, hay que comenzar por señalar que el excepcionalismo neoconservador parte de una dicotomía que divide el mundo entre el bien, con los EE.UU. como máximo representante de la democracia occidental, y el mal, con los 'Estados canallas' como máximos exponentes de los enemigos de América. Los EE.UU. encarnan el bien porque, según los neoconservadores, sus valores son superiores a los del resto de países del mundo. Como correlato de esta visión binaria, tenemos la identificación neoconservadora de los valores e intereses de los EE.UU. con los valores e intereses del resto del mundo; identificación que, en definitiva, supone que lo que es bueno para los EE.UU. es, por definición, bueno para el mundo. Dentro de esta lógica, cuando los EE.UU. actúan internacionalmente, por unilaterales que fueran sus intervenciones, el resultado siempre es mejor que si no hubieran actuado. Ello constituye tanto la premisa como la justificación última de todas las acciones estadounidenses.

La dimensión del poder militar es otro de los rasgos distintivos del excepcionalismo americano según la doctrina neoconservadora ${ }^{9}$. Junto a la superioridad moral de sus valores, los EE.UU. poseen una superioridad militar que debe ser mantenida y aumentada. Desde este punto de vista, la fuerza y los valores guardan una indudable relación de complementariedad: la primera es la garantía de supervivencia de los segundos, y estos, a su vez, son la fuente de legitimidad de aquélla. Sin el respaldo de una fuerza militar capaz de defender los valores americanos, estos estarían inermes ante sus enemigos y no tendrían posibilidad de pervivir en un mundo hostil; igualmente, sin el respaldo legitimador que conceden los valores a la acción militar americana, ésta quedaría reducida al ejercicio de un poder desnudo y brutal. Además, el uso de la fuerza es a veces necesario no sólo para la defensa sino también para la difusión y expansión de los valores estadounidenses por todo el mundo ${ }^{10}$. En este punto es necesario

Véanse: Lipset, Seymour Martin (2000): El excepcionalismo norteamericano: una espada de dos filos, México, D.F., Fondo de Cultura Económica, p. 14 y Tocqueville, Alexis de (2002) [1840]: La democracia en América, 2, Madrid, Alianza Editorial, p. 51.

${ }^{7}$ Lipset, op. cit., p. 15.

${ }^{8}$ Chernus, Ira (2006): Monsters to Destroy: The Neoconservative War on Terror and Sin, Boulder, Paradigm Publishers, p. 34.

${ }^{9}$ En este sentido, desde una perspectiva crítica con el neoconservadurismo, véase: Hoffmann, Stanley: "The High and the Mighty", The American Prospect, 19 de diciembre 2003, en http://prospect.org/article/high-andmighty.

${ }^{10}$ Así, según Abrams: "Maintaining American military strength is not only vital to a successful foreign policy. The 1970 s and 1980s demonstrated that the success of democracy in the world is directly related to that 
subrayar la gran importancia que la llamada doctrina del Destino Manifiesto, y el sentido de misión que ésta lleva implícito, tiene a la hora de mantener vivo el poder militar americano y establecer la necesaria conexión entre éste y los valores de la nación ${ }^{11}$.

La política exterior que propone el neoconservadurismo se basa en todo momento en la idea de que los EE.UU. son una nación excepcional y que, en consecuencia, ha de actuar en la escena internacional de acuerdo con su excepcionalidad. De esta manera, en la concepción neoconservadora el excepcionalismo sirve para justificar y legitimar tanto la promoción de la democracia como el unilateralismo, enraizando históricamente su doctrina con la cultura política de su país y presentándola, así, como distintivamente estadounidense.

En los últimos años tras la controvertida presidencia de Bush y la llegada de Obama al poder, el debate en torno al excepcionalismo americano ha vivido un nuevo y encendido auge $^{12}$. Según los neoconservadores, Obama ha abandonado el excepcionalismo americano: no cree que los EE.UU. sean una nación única ni que tengan una misión en el mundo, ni cree, por lo tanto, en la superioridad moral y militar de los EE.UU. ${ }^{13}$. La política exterior desarrollada por Obama desde 2009 confirma sus palabras en la cumbre de la OTAN de Estrasburgo en los albores de su presidencia ("I believe in American exceptionalism, just as I suspect that the Brits believe in British exceptionalism and the Greeks believe in Greek exceptionalism" ${ }^{14}$ ), y deja claro para los neoconservadores que ésta rechaza por completo la visión excepcionalista de los EE.UU. que ellos defienden. Frente al anti-excepcionalismo de Obama los neoconservadores reivindican de nuevo la visión excepcionalista de Ronald Reagan $^{15}$, en lo que vendría a ser un ritornello neoconservador de mediados de los años noventa, cuando Kagan y Kristol reclamaban una política exterior neo-reaganiana para los EE.UU.

Para los neoconservadores la ausencia del excepcionalismo en la visión política de Obama está directamente relacionada con otra cuestión fundamental sobre la política exterior americana: el del declive de los EE.UU. A su juicio, la puesta en práctica de una política exterior carente de una matriz excepcionalista trae como consecuencia la decadencia de la nación en la esfera internacional.

\section{El 'declinismo' como amenaza al orden mundial americano}

Según la doctrina neoconservadora, sobre la hegemonía americana actualmente se ciernen dos peligros estrechamente relacionados: por una parte, una nueva oleada 'declinista' impulsada

strength". Véase: Abrams, Elliott (1995): Security and Sacrifice: Isolation, Intervention, and American Foreign Policy, Indianapolis, Hudson Institute, p. 118.

${ }^{11}$ Para los neoconservadores la existencia de ese sentido de misión es fundamental, pues, en ausencia del mismo, el pueblo americano caerá en la tentación aislacionista y dará su apoyo a recortes presupuestarios en defensa y política exterior. Véase: Dorrien, Gary (2004): Imperial Designs: Neoconservatism and the New Pax Americana, New York, Taylor \& Francis Books, p. 128.

${ }^{12}$ Brooks, Stephen (2013): American Exceptionalism in the Age of Obama, New York, Routledge, pp. 1-17.

${ }^{13}$ Según John Podhoretz, "Obama's social-democratic statism is setting the United Stated on a course for disaster and that his anti-exceptionalism foreign policy is setting the world on a course for nihilistic chaos": Podhoretz, John: "Time to Get Serious", Commentary, vol. 135, Issue 4 (2013), p. 1; Podhoretz, John: "Taking Obama's Foreign Policy Seriously", Commentary, vol. 135, Issue 5 (2013), p. 1.

14 "News conference by President Obama", Strasbourg, France, The White House, (4 de abril 2009), en http://www.whitehouse.gov/the-press-office/news-conference-president-obama-4042009.

${ }^{15}$ Véanse: Barone, Michael (2013): "Restoring Reaganesque Exceptionalism in American Politics" en DUNN, Charles W. (ed.): American Exceptionalism: the origins, history, and future of the nation's greatest strength, Lanham, Rowman \& Littlefield Publishers, pp. 143-150; Hayward, Steven F. (2013): "Back to the Future: Ronald Reagan Exceptionalism", en DUNN, Charles W. (ed.): op. cit., pp. 151-160. 
por un importante sector político, académico y mediático dentro de los EE.UU.; y, por otra, la política exterior del presidente Barack Obama, que habría asumido los principios fundamentales del discurso 'declinista'.

El llamado 'declinismo' (declinism), nuevamente en boga desde la crisis económica y financiera de 2008, preconiza que el poder de los EE.UU. ha entrado en decadencia y que es inevitable que pierdan su condición de hegemón: haga lo que haga la superpotencia, el fin de la unipolaridad es inevitable. Es más, sus esfuerzos por mantenerla unilateralmente mediante el uso de la fuerza han acelerado su descomposición. En este sentido, los 'declinistas' acusan a la Administración Bush de haber desarrollado una política exterior unilateralista y militarista que ha dañado enormemente la economía y el poder blando americano, poniendo a los EE.UU. al límite del imperial overstretch. De este modo, la hegemonía americana nacida del final de la Guerra Fría es insostenible: los EE.UU. no disponen ya de los recursos económicos necesarios para mantenerla ${ }^{16}$. Asimismo, los EE.UU. no sólo afrontan graves problemas internos sino que en el escenario internacional están teniendo lugar cambios en la distribución del poder entre las grandes potencias. El auge de los llamados BRIC —Brasil, Rusia, India y China - ha propiciado la difusión del poder global americano hacia estas potencias emergentes, especialmente hacia China. La consecuencia del diagnóstico 'declinista' es, por ende, clara: los EE.UU. deben reducir notablemente su papel internacional, sobre todo en lo referido al aventurismo militar de la pasada década, para dedicarse a solucionar sus graves problemas internos ${ }^{17}$.

A juicio de los neoconservadores, el 'declinismo' empuja a los EE.UU. al ensimismamiento aislacionista y éste lleva al mundo sin remedio a la multipolaridad. En este sentido, no hay que olvidar que estos consideran que la multipolaridad es un sistema internacional del todo indeseable para los EE.UU. ${ }^{18}$, pues un mundo multipolar sería necesariamente un mundo más inseguro y peligroso y menos afín a la democracia, esto es, un lugar mucho más hostil a los intereses y valores estadounidenses ${ }^{19}$. La pérdida de capacidad de moldear el mundo conforme a sus intereses y valores que implica el repliegue global de los EE.UU., supone una mayor vulnerabilidad de la superpotencia frente a las amenazas que no sólo debilita la seguridad nacional sino que pondría en peligro la supervivencia del propio modelo americano.

Pero si los efectos de la retirada americana y la llegada de la consiguiente multipolaridad serían deletéreos para los EE.UU. no menos lo serían para el mundo, pues sólo la hegemonía americana es capaz de proveer la paz, la seguridad y la justicia internacionales. En efecto, no sólo la unipolaridad proporciona un mundo pacífico —en el sentido de que no existen guerras entre las grandes potencias- y seguro frente a un eventual mundo multipolar, sino que es el "mundo más justo que cualquier otro que podamos concebir" ${ }^{20}$ ya que la alternativa multipolar sólo beneficia a las autocracias ${ }^{21}$. De este modo, según Robert Kagan el fin del llamado 'orden mundial americano' (American World Order) traería consigo tres consecuencias nefastas para el mundo. En primer lugar, implicaría la

\footnotetext{
${ }^{16}$ Quinn, Adam (2011): "The art of declining politely: Obama's prudent presidency and the waning of American Power", International Affairs, vol. 87, no 4 (2011), pp. 805-807.

${ }^{17}$ Lieber, Robert J. (2008): "Falling Upwards: Declinism, the Box Set", World Affairs, (Verano 2008), en http://www.worldaffairsjournal.org/article/falling-upwards-declinism-box-set.

${ }_{18}$ Cooper, Danny (2011): Neoconservatism and American Foreign Policy. A critical analysis, New York, Routledge, pp. 109-114.

${ }^{19}$ Kristol, William y Kagan, Robert (2005) [2000]: "Interés nacional y responsabilidad global" en Kristol, William y Kagan, Robert (eds.): Peligros presentes. Soluciones de la nueva Administración Bush ante una civilización amenazada, trad. y adaptación de Ignacio de la Rasilla del Moral, Córdoba, Almuzara, p. 69.

${ }^{20}$ Ibid.

${ }^{21}$ Kagan, Robert (2008): El retorno de la Historia y el fin de los sueños, Madrid, Taurus, pp. 145-148.
} 
vuelta de la guerra entre las grandes potencias que lucharían por el poder. La hegemonía estadounidense es garantía de estabilidad en Europa, Asia y Oriente Medio: si los EE.UU. se retiran de estas regiones, las mismas se convertirán en escenarios de lucha por el poder por parte de las grandes potencias para cubrir el vacío de poder dejado por los EE.UU. En segundo lugar, se produciría una retirada de la democracia del mundo, puesto que el fin del liderazgo estadounidense en la promoción de la democracia sería suplido por grandes potencias autocráticas como China y Rusia. Por último, se produciría el debilitamiento de la economía de mercado global a la que los EE.UU. han contribuido de manera decisiva en los últimos sesenta años ${ }^{22}$.

Por lo tanto, si los EE.UU. deciden centrarse en resolver sus problemas internos y renunciar a las cargas que implica la primacía mundial estarían cometiendo, en palabras de Kagan, un "suicidio preventivo de superpotencia" (preemptive superpower suicide) ${ }^{23}$. Los neoconservadores refutan, en consecuencia, la doctrina 'declinista' y afirman que los EE.UU. no están en decadencia: pese a la crisis económica y la emergencia de otras potencias, conservan su primacía militar y su economía sigue siendo la más importante del mundo y se está recuperando de la crisis como ha sucedido en otras ocasiones a lo largo del siglo $\mathrm{XX}^{24}$.

Como antes hemos apuntado, según los neoconservadores, en los últimos seis años la Administración Obama ha hecho suya la lógica 'declinista' y está propiciando un orden multipolar mediante una política exterior de retirada del mundo que ha dejado de defender y promover la democracia y que ha recortado sustancialmente el gasto militar debilitando el poder estadounidense ${ }^{25}$. Por ende, Obama encarna el nuevo 'declinismo' americano con una política exterior carente tanto de voluntad hegemónica como de claridad moral. Así pues, para los neoconservadores el declive de los EE.UU. es una elección política y el presidente Obama ha optado claramente por esta opción ${ }^{26}$. De hecho, la pérdida de influencia que los EE.UU. han experimentado en el mundo durante los últimos años es consecuencia principal y directa de la política exterior desarrollada por la Administración Obama ${ }^{27}$. El New Liberalism representado por Obama no cree en la legitimidad moral de la hegemonía americana y culpa al unilateralismo y a la arrogancia estadounidenses de los males del mundo ${ }^{28}$, es decir, vuelve al discurso del blame America first típico de la izquierda relativista de los años setenta. Según Kagan el cambio fundamental se ha producido en los EE.UU. a nivel conceptual: Obama ha catalizado el deseo de 'normalidad' de la mayoría de la población americana, esto es, el deseo de renunciar a las cargas que comporta la responsabilidad global que los EE.UU. han adquirido desde 1945. La política exterior de Obama ha dado lugar a un periodo de repliegue americano; el problema fundamental es que ese periodo no sea un paréntesis de ocho años sino que dé lugar a una etapa prolongada propiciando, así, un cambio fundamental en el orden internacional surgido tras la $\mathrm{SGM}^{29}$.

En consecuencia, los neoconservadores estiman que la multipolaridad es una posibilidad evitable y que la hegemonía estadounidense puede perdurar durante décadas. En este sentido, afirman que el 'declinismo' es un discurso que irrumpe periódicamente en la política

\footnotetext{
${ }^{22}$ Kagan, Robert (2012): The World America Made, New York, Knopf, pp. 68-101.

${ }^{23}$ Ibid., p. 7.

${ }^{24}$ Ibid., pp. 105-107.

${ }^{25}$ Muravchik, Joshua: "The Abandonment of Democracy", Commentary, vol. 128 (2009), pp. 21-26.

${ }^{26}$ Krauthammer, Charles: "Decline is a Choice: The New Liberalism and the end of American ascendancy", The Weekly Standard, Vol. 15, nº. 5, 19 de octubre de 2009, en http://www.weeklystandard.com/Content/Public/Articles/000/000/017/056lfnpr.asp.

${ }^{27}$ Bolton (2014): op. cit.

${ }^{28}$ Krauthammer (2009): op. cit., p. 2.

${ }^{29}$ Kagan, Robert (2014): "Superpowers Don't Get to Retire", The New Republic, 26 de mayo 2014, pp. 1 y 2, en http://www.newrepublic.com/article/117859/allure-normalcy-what-america-still-owes-world.
} 
americana y que ya otras veces se ha revelado erróneo tanto en su diagnóstico como en sus prescripciones $^{30}$. Esta nueva irrupción 'declinista' sería, así, más una reacción motivada ideológicamente por parte de sectores realistas y liberales frente a la política exterior de George W. Bush que una descripción adecuada de la realidad estadounidense y de su posición actual y futura en el mundo ${ }^{31}$.

\section{El abandono de la democracia}

Tras la Guerra Fría, la promoción de la democracia sustituyó al anticomunismo como motor ideológico de la doctrina neoconservadora. Desde entonces, los neoconservadores han hecho de ésta uno de los principales elementos de su programa político. El llamado idealismo democrático se ha convertido, así, en una característica distintiva fundamental del neoconservadurismo, en virtud de la cual los EE.UU. tienen el deber de actuar en aras de la expansión global de la democracia porque un mundo democrático va en beneficio tanto de los intereses como de los valores fundacionales de los EE.UU. ${ }^{32}$. A juicio de Muravchik, aunque con las lógicas diferencias de cada momento histórico, los EE.UU. han sido coherentes en líneas generales con su finalidad fundacional y desde hace doscientos años se han erigido en el principal actor internacional en la difusión de la democracia ${ }^{33}$. En este mismo sentido, Ledeen señala que los EE.UU. son una potencia revolucionaria y transformadora que históricamente ha contribuido de manera decisiva a cambiar el mundo y al progreso de la humanidad $^{34}$.

En consecuencia, los neoconservadores afirman la necesidad de exportar la democracia americana por dos razones fundamentales que se presentan de modo complementario e indisociable: por un lado, la democracia y su difusión forman parte sustancial de la identidad nacional de los EE.UU. y exportándola los EE.UU. vindican sus orígenes nacionales y cumplen con su misión fundacional; por otra parte, es un medio imprescindible para garantizar tanto la seguridad como la primacía americanas en el siglo XXI. Tras el 11-S, y en el marco de la Guerra contra el Terror, la promoción de la democracia debía convertirse en un elemento imprescindible de la política exterior americana. A partir de esa fecha, para los neoconservadores ésta ha tenido como objetivo político principal la transformación del llamado 'Gran Oriente Medio', en el entendido de que la falta de democracia en esta macroregión está en la raíz del terrorismo islamista y del islamismo radical que lo sustenta ideológicamente, suponiendo una amenaza existencial para los EE.UU. ${ }^{35}$.

A juicio de los neoconservadores, Obama ha destacado desde el principio de su mandato por el flagrante abandono de los derechos humanos y de la promoción de la democracia en su política exterior $^{36}$. El presidente demócrata ha escapado de Irak y no se ha comprometido

\footnotetext{
${ }^{30}$ Lieber, (2008), op. cit.

31 Ibid.

${ }^{32}$ Muravchik, Joshua (1996): The Imperative of American Leadership: A Challenge to Neo-Isolationism, Washington, DC, The American Enterprise Institute Press, p. 173, 175 y 176.

${ }^{33}$ Ibid., pp. 180 y 181.

${ }^{34}$ Ledeen, Michael (2001): Tocqueville on American Character: Why Tocqueville's Brilliant Exploration of the American Spirit is as Vital and Important Today as It Was Nearly Two Hundred Years Ago, New York, St. Martin's Griffin, p. 202.

${ }^{35}$ Frum, David y Perle, Richard (2004): An End to Evil: How to Win the War on Terror, New York, Ballantine Books, pp. 134-139; Donnelly, Thomas (2004): Operation Iraqi Freedom: a Strategic Assessment, Washington, DC, AEI Press, pp. 32, 108-112.

${ }^{36}$ Muravchik, op. cit., p. 21.
} 
como debiera con la promoción de la democracia en la llamada 'primavera árabe ${ }^{37}$. En ambos casos, el problema de fondo es que, al parecer de los neoconservadores, Obama es un relativista que practica la equivalencia moral y que, por ende, no cree en la superioridad de los valores americanos ${ }^{38}$.

Por otro lado, Kagan en 2008 ya advertía que Rusia y China estaban comportándose como grandes potencias y auguraba un conflicto entre democracias y autocracias ${ }^{39}$. Como consecuencia del repliegue americano, en estos años se ha producido una retirada de la democracia en el mundo que ha venido acompañada de un avance simultáneo de la autocracia $^{40}$. Por lo tanto, para los neoconservadores la difusión de la democracia en el mundo está indisociablemente unida a la hegemonía estadounidense: no hay otra superpotencia democrática capaz de sustituir a los EE.UU. en el papel democratizador que han ejercido a lo largo de su historia; antes bien, el vacío que deje Washington será llenado por las potencias autocráticas, revirtiendo la expansión democrática de las últimas décadas ${ }^{41}$.

\section{Israel: la traición de la democracia}

El apoyo incondicional a Israel se ha convertido en uno de los elementos más distintivos y conocidos del neoconservadurismo ${ }^{42}$. No en vano, el debate sobre el conflicto árabe-israelí suscitado en el seno del liberalismo americano y del Partido Demócrata desde finales de los sesenta y principios de los setenta fue uno de los detonantes del propio surgimiento del movimiento neoconservador ${ }^{43}$.

El idealismo democrático neoconservador no sólo exige que los EE.UU. lleven la democracia allí donde está ausente, sino que también la defiendan allí donde ya exista y se halle en peligro. En este último sentido, Israel es para los neoconservadores el paradigma de una democracia rodeada de enemigos que ansían su destrucción. La situación de Israel permite visualizar perfectamente la lucha entre tiranía y democracia en la que los EE.UU. no pueden permanecer equidistantes: deben apoyar incondicionalmente a una democracia asediada como la israelíi ${ }^{44}$. Esta visión se fundamenta tanto en razones estratégicas como morales y conduce a entronizar la relación especial de los EE.UU. con Israel como el vector fundamental de la política americana hacia la región. Según los neoconservadores, entre los EE.UU. e Israel existe una identidad de intereses y valores que justifica y hace imprescindible el total respaldo estadounidense al Estado hebreo ${ }^{45}$.

A partir de esta premisa, la posición neoconservadora hacia Israel y el conflicto de Oriente Medio se pueden resumir en tres principio fundamentales que guardan una estrecha

\footnotetext{
37 Boot, Max (2013): "The Myth of Authoritarian Stability", Commentary, 29 de julio de 2013, en http://www.commentarymagazine.com/2013/07/29/the-myth-of-authoritarian-stability/.

38 Tobin, Jonathan S.: "Obama's Age of Moral Equivalence", Commentary, 4 de junio de 2009, en http://www.commentarymagazine.com/2009/06/04/obama\%E2\%80\%99s-age-of-moral-equivalence/.

${ }^{39}$ Kagan (2008): op. cit.

${ }^{40}$ Kagan (2014): op. cit., p. 1.

${ }^{41}$ En este sentido: Ibid., pp. 17 y 18.

${ }^{42}$ Así, según Boot, el apoyo a Israel es "a key tenet of neoconservatism": Boot, Max (2002): "What the Heck is a 'Neocon'?", The Wall Street Journal, 30 de deciembre de 2002.

43 Véase: Heilbrunn, Jacob (2008): They Knew They Were Right: The Rise of the Neocons, New York, Doubleday, pp. 81-86.

${ }^{44}$ Dorrien, op. cit., p. 204.

${ }^{45}$ Según los neoconservadores, desde el punto de vista estratégico, Israel es el principal y más fiable aliado de los EE.UU. en la región, precisamente por su carácter democrático; mientras que desde el punto de vista axiológico y moral, Israel es parte integrante e integral de Occidente, y, por lo tanto, abandonar la defensa de su causa frente a sus enemigos equivaldría a abandonar la defensa de la democracia frente a la tiranía. Véase: Ibid.
} 
conexión: rechazo radical al proceso de paz $^{46}$, búsqueda de la transformación regional por parte de los EE.UU e Israel y apoyo al expansionismo territorial israeli ${ }^{47}$. El alineamiento neoconservador con las posiciones del Likud israelí es evidente y, por ello, los neoconservadores han sido calificados como 'sionistas de línea dura' (hardline Zionists) ${ }^{48}$.

Para los neoconservadores la resolución del histórico conflicto árabe-israelí no es el principal problema de la región, de modo que no debe ser el primer paso para resolver los problemas de ésta, sino el último ${ }^{49}$. A su parecer, el terrorismo islámico y el islamismo radical no se alimentan del conflicto árabe-israelí sino de la ausencia de democracia en los países árabes y, por ende, la prioridad es transformar la cultura política de la región mediante la extensión de la democracia e impedir que Irán, enemigo existencial declarado de Israel, logre el arma nuclear. La transformación democrática de la región irá en beneficio del interés nacional de los EE.UU. y de Israel. Una vez que estos objetivos se logren, en un entorno democrático y seguro será posible y relativamente sencillo resolver el conflicto árabe-israelí ${ }^{50}$. Igualmente, responsabilizan completamente a los países árabes y a la Autoridad Nacional Palestina de la persistencia del conflicto ${ }^{51}$. La negativa contumaz de todos ellos a reconocer el derecho a existir de Israel, el terrorismo palestino y, en última instancia, la propia ausencia de democracia en la región —en ningún caso la ocupación israelí de territorios palestinosconstituyen el núcleo esencial del problema ${ }^{52}$.

A juicio de la doctrina neoconservadora, existen una serie de asuntos sobre los que no cabe transacción alguna de modo que ni Israel ni los EE.UU. pueden realizar concesiones para lograr la paz con los palestinos ni con otro país de la región: el restablecimiento de las fronteras anteriores a la Guerra de los Seis Días conforme a las resoluciones del Consejo de Seguridad de la ONU, el retorno de los refugiados palestinos y la soberanía de Jerusalén ${ }^{53}$. En consecuencia, los neoconservadores consideran que los EE.UU. sólo deberían reconocer un Estado palestino cuando se cumpla un doble requisito: que funcione como un país democrático antes incluso de proclamarse como Estado; y que el mismo se proclame únicamente sobre los territorios actualmente bajo jurisdicción palestina en Cisjordania y en la franja de Gaza, es decir, reconociendo los asentamientos israelíes y renunciando al retorno de los refugiados, a la capitalidad de Jerusalén y a las fronteras anteriores a la guerra de 1967.

Los neoconservadores responsabilizan a la Administración Obama del serio deterioro que han sufrido las relaciones entre los EE.UU. e Israel desde su llegada al poder. A su

\footnotetext{
${ }^{46}$ Podhoretz, Norman: "Oslo: The Peacemongers Returm", Commentary, Vol. 112, Issue 3 (Octubre 2001), pp. 21-33. La oposición neoconservadora a los Acuerdos de Oslo alcanza el paroxismo en la voz de Charles Krauthammer, para quien los mismos constituyen, dado su carácter apaciguador y suicida, "uno de los grandes desastres en la Historia judía". véase: Krauthammer, Charles: "Oslo and the End of Illusion", Bella Wexner Memorial Lecture, $\mathrm{n}^{\circ} 2$ (2003), pp. 4-6. Una crítica más reciente al proceso de paz y a la obsesión de la Administración Obama con el mismo, calificado como "proceso de terror" para Israel, en: Kristol, William (2014): "With Israel, Against Terror", The Weekly Standard, 21 de noviembre del 2014, en http://www.foreignpolicyi.org/content/israel-against-terror.

${ }^{47}$ Los neoconservadores consideran que Israel debe abandonar el principio de 'paz por territorio' y renunciar a la idea de lograr una paz global en la región con los países árabes. Véase: Perle, Richard et al. [Study Group on a New Israeli Strategy toward 2000] (1996): "A Clean Break: a New Strategy for Securing the Realm", Institute for Advanced Strategic and Political Studies, Jerusalem, Washington, DC, June 1, pp. 2 y 3.

${ }^{48}$ Dorrien, op. cit. pp. 195-198.

${ }^{49}$ Frum, y Perle, op. cit., pp. 160 y 161.

${ }^{50}$ Dorrien, op. cit., p. 209.

${ }^{51}$ Según Sharansky, "la dictadura de la ANP es la principal fuente de sufrimiento del pueblo palestino [...] sólo si los palestinos construyen una democracia habrá paz": Sharansky, Natan con Dermer, Ron (2006): Alegato por la democracia: la fuerza de la libertad para acabar con la tiranía y el terror, Barcelona, Gota a Gota, p. 294.

${ }^{52}$ En este sentido, véase: Ibid., pp. 215, 216 y 294.

${ }^{53}$ Krauthammer, Charles: "What Obama did to Israel", The Washington Post, 21 de mayo de 2011.
} 
entender, las desavenencias existentes con el gobierno del primer ministro Benjamin Netanyahu se deben a que Obama ha mantenido posiciones de una equidistancia inaceptable con un aliado vital en la región. En este sentido, su insistencia en defender la resolución del conflicto árabe-israelí a partir de las fronteras anteriores a la guerra de 1967 conforme a las resoluciones de las Naciones Unidas, su enorme presión sobre Israel en lo relativo a los asentamientos israelíes en Cisjordania y el diálogo y las negociaciones nucleares con Teherán, al que nos referiremos infra, han sido los puntos más rechazables de su política hacia el Estado hebreo. Todo ello ha dado, según la doctrina neoconservadora, legitimidad a dos enemigos existenciales de Israel y de la democracia: la organización terrorista Hamas y el régimen iraní. Obama ha traicionado a Israel y, de este modo, la causa de la democracia en una región clave para los intereses y valores de los EE.UU ${ }^{54}$. Para William Kristol, la política de Obama respecto de Israel y el conflicto de Oriente Medio no deja lugar a duda alguna: nos hallamos ante un presidente anti-israeli ${ }^{55}$.

En última instancia, el problema de Obama con Israel se debe, a juicio de los neoconservadores, a la falta de claridad moral del presidente americano, debido a la cual éste no es capaz de distinguir entre amigos y enemigos de los EE.UU., lo que le lleva a castigar a los primeros y a apaciguar a los segundos, actuando así contra los intereses y valores de la nación ${ }^{56}$.

\section{La falta de claridad moral: las negociaciones con Irán o el apaciguamiento del mal}

El neoconservadurismo se ha definido desde sus orígenes y a lo largo de sus distintas etapas como una doctrina profundamente moralista que ha hecho de la lucha contra el relativismo moral y sus perniciosos efectos políticos y sociales una de sus principales banderas. A juicio de los neoconservadores, el relativismo, como corriente filosófica aplicada a la práctica política, genera en sus partidarios una incapacidad sistemática para defender la tradición, la identidad $y$, en consecuencia, la propia seguridad nacional ${ }^{57}$. El relativismo no sólo deslegitima la política exterior americana frente a sus enemigos, sino que induce a los partidarios del mismo a apoyar a estos frente a los EE.UU. ${ }^{58}$. De este modo, el relativismo es, según los neoconservadores, la mayor amenaza intelectual e ideológica que se cierne en la actualidad sobre los valores y tradiciones de los EE.UU. en particular y de Occidente en su conjunto.

Una primera consecuencia del moralismo neoconservador y de su batalla contra el relativismo alude al papel que han de desempeñar los valores y los principios morales en la política exterior. Para la necesaria regeneración moral de la nación es imprescindible llevar a cabo una política exterior remoralizada ${ }^{59}$. En este sentido, para los neoconservadores no cabe admitir la clásica escisión realista entre mundo interno y mundo internacional concebidos como dos ámbitos completamente separados en los que operan códigos morales y axiológicos distintos. Piensan, en cambio, que la política exterior debe estar informada por los mismos

\footnotetext{
${ }^{54}$ Ledeen, Michael A. (2009a): Obama's Betrayal of Israel, New York, Encounter Books.

${ }^{55}$ Kristol, op. cit.

${ }^{56}$ Muravchik, Joshua (2010b): Obama's Radical Transformation of America: Year One, New York, Encounter Books.

${ }^{57}$ Murray, Douglas (2006): Neoconservatism: Why we need it, New York, Encounter Books, p. 101.

${ }^{58}$ Ibid., p. 158.

${ }^{59}$ Kristol, William y Kagan, Robert: "Toward a Neo-Reaganite Foreign Policy", Foreign Affairs, vol. 75, Iss. 4 (Julio/agosto 1996), p. 31.
} 
valores y principios morales que rigen en la política interna, contradiciendo, de este modo, el principio de doble moralidad típico de las teorías realistas ${ }^{60}$.

El moralismo neoconservador se pone claramente de manifiesto en la ya mencionada noción de claridad moral (moral clarity), concebida como un instrumento imprescindible para combatir el relativismo moral. Este concepto típicamente neoconservador y fundamental en el entramado teórico del neoconservadurismo ${ }^{61}$, consiste en la capacidad o cualidad necesaria para distinguir entre el bien y el mal, es decir, entre los amigos y los enemigos de la democracia y la libertad (y por tanto, de los EE.UU.) de la que han de estar dotados los gobernantes americanos para dirigir adecuadamente el destino de la nación ${ }^{62}$. Los neoconservadores, en línea con su característico occidentalismo americanocéntrico, afirman sin ambages la superioridad moral de los valores de Occidente, con los EE.UU. como máximo exponente de los mismos. Esta superioridad de los valores occidentales/americanos constituye, por consiguiente, la sólida base sobre la que ha de asentarse la claridad moral.

Según la doctrina neoconservadora, la expresión más perversa del relativismo y de la equivalencia moral que éste comporta en el ámbito de las relaciones internacionales es el apaciguamiento $^{63}$. Se trata, en efecto, de otra noción clave en el pensamiento neoconservador desde sus orígenes hasta nuestros días ${ }^{64}$. Contradiciendo la definición clásica de Paul Kennedy ${ }^{65}$, los neoconservadores consideran que el apaciguamiento es un concepto que posee un significado exclusivamente negativo: equivale a la rendición frente al enemigo antes incluso de confrontarlo. Así, el apaciguamiento es completamente inadmisible como instrumento de la política exterior americana: a los enemigos sólo cabe combatirlos hasta derrotarlos; lo contrario, fortalece sus posiciones y acaba indefectiblemente agravando la amenaza que representan. Dicho en otros términos: para los neoconservadores el apaciguamiento es una muestra de debilidad y cobardía, producto del relativismo moral, que sólo conduce a quien lo practica a la derrota ${ }^{66}$.

Por ello, es esencial que los líderes políticos occidentales en general y los americanos en particular, a la hora de enfrentarse a las amenazas que acechan a sus países, tengan esta capacidad de discernimiento moral que poseían, a juicio de los neoconservadores, grandes estadistas como Theodore Roosevelt, Winston Churchill, Harry Truman, Ronald Reagan,

\footnotetext{
${ }^{60}$ De hecho, los neoconservadores han criticado de manera recurrente la amoralidad del realismo y han denunciado la 'bancarrota' moral y la 'mezquindad' de la política exterior realista en diversas y significativas ocasiones, como cuando la Administración Bush, en el marco de la Guerra del Golfo de 1991, detuvo su acción militar una vez liberado Kuwait y optó por no avanzar hacia Bagdad para derrocar a Saddam Hussein. Véase: Kristol, William y Kaplan, Lawrence F. (2004) [2003]: La Guerra de Irak. En defensa de la democracia y la libertad, comentado, adaptado y revisado por Juan Jesús Mora, Córdoba, Almuzara, pp. 91, 95 y 96.

${ }^{61}$ Bennett, William J. (2003): Why We Fight: Moral Clarity and the War on Terrorism, Washington, DC, Regnery, pp. 9-22; Murray, op. cit., pp. 46-53.

${ }^{62}$ Kristol, Irving (2005) [2003]: "The Neoconservative Persuasion. What it was and what it is" en Stelzer, Irwin (ed.), Neoconservatism, London, Atlantic Books, p. 36.

${ }^{63}$ En el imaginario neoconservador, el ejemplo histórico por antonomasia de apaciguamiento es el Pacto de Múnich de 30 de septiembre de 1938, donde Chamberlain claudicó ante Hitler y fortaleció el expansionismo nazi que dio lugar a la Segunda Guerra Mundial y al Holocausto. Dicho hecho histórico se convierte en el máximo paradigma de los males que implica el apaciguamiento como expresión práctica directa del relativismo moral en la política internacional.

${ }^{64}$ Así, durante la Guerra Fría, Podhoretz fue un acérrimo crítico de "la cultura del apaciguamiento" y de su impacto en la política exterior americana; véase: Podhoretz, Norman (1980): The Present Danger: Do We Have the Will to Reverse the Decline of American Power?, New York, Simon \& Schuster, pp. 79-85.

${ }^{65}$ Kennedy afirma que, entre 1865 y 1939 , la política exterior británica estuvo presidida por el apaciguamiento y reivindica la acepción originaria y no peyorativa que el término tuvo precisamente hasta las negociaciones de Múnich: Kennedy, Paul (1984): Strategy and Diplomacy, 1870-1945: Eight Studies, London, Allen \& Unwin, p. 16.

${ }^{66}$ En este sentido, véase Podhoretz (1980), op. cit., pp. 84 y 85.
} 
Margaret Thatcher o George W. Bush. Así, según los neoconservadores, la posesión de sólidos principios morales y la determinación de ponerlos en práctica es una cualidad imprescindible para todo presidente de los EE.UU., cualidad de la que, a su juicio, carece por completo Barack Obama.

Un ejemplo claro y representativo de la importancia de la claridad moral en el neoconservadurismo, es la posición neoconservadora respecto del conflicto existente entre la comunidad internacional y la República Islámica de Irán por su controvertido programa nuclear. Pues bien, los neoconservadores entienden que dada su naturaleza tiránica y terrorista es imposible alcanzar un acuerdo fiable y duradero con el régimen de los ayatolás ${ }^{67}$. Desde su llegada al poder en 1979, éste se ha convertido en un declarado enemigo de los EE.UU. que, al igual que Hitler y Stalin, desea destruir Occidente ${ }^{68}$. Asimismo, ante su voluntad declarada de aniquilar al Estado de Israel, los EE.UU. no deben permitir bajo ningún concepto que Irán llegue a obtener el arma nuclear ${ }^{69}$. La única salida posible al conflicto será, por ende, desbaratar los planes iraníes mediante el uso de la fuerza, que deviene legítimo por la propia naturaleza maligna de la teocracia iraní. En consecuencia, los neoconservadores recomiendan promover un cambio de régimen mediante el apoyo directo de los EE.UU. a la disidencia interna y/o lanzar un ataque preventivo contra Irán similar al efectuado por Israel en Osirak en $1981^{70}$.

A la vista de sus posiciones sobre este asunto, no es de extrañar que los neoconservadores hayan criticado severamente la política desarrollada por la Administración Obama hacia Irán, tachándola de apaciguadoras ${ }^{71}$, en el entendido de que la propia interlocución con Teherán equivale a una rendición preventiva que sólo postergará y agravará la amenaza. Por ello, no puede sorprender que los neoconservadores se hayan opuesto radicalmente a las negociaciones iniciadas en Ginebra durante el otoño de 2013 (las llamadas negociaciones P5+1, en EE.UU., o E3+3, en Europa) y que hayan evocado de inmediato la alargada sombra de la Conferencia de Múnich. Así, en opinión de Krauthammer, el acuerdo provisional alcanzado con Irán el 24 de octubre de 2013 fue el peor logrado desde el apaciguamiento de Hitler en 1938, mientras que 2014 y 2015 pasarán a la historia por ser los años en los cuales Obama se rindió ante las pretensiones nucleares de Irán $^{72}$.

\footnotetext{
${ }^{67}$ Frum, y Perle, op. cit., p. 83; Murray, op. cit., pp. 83 y 89; Ledeen, Michael A. (2007): The Iranian Time Bomb: The Mullah Zealots' Quest for Destruction, New York, St. Martin's Press, pp. 29-71.

${ }^{68}$ Ledeen, Michael A. (2009b): Accomplice to Evil: Iran and the War Against the West, New York, St. Martin's Press, p. 4.

${ }^{69}$ Ledeen (2007), op. cit., pp. 91 y 247. Según Ledeen, aunque no existiera un programa nuclear, Irán sería una "amenaza mortal" para Israel y los EE.UU., de modo que, con mayor razón, "the mullah's drive for atomic bombs make the threat a matter of live and death": Ledeen (2009a), op. cit., p. 30.

${ }^{70}$ Frum y Perle, op. cit., p. 93; Leeden, (2007), op. cit., pp. 206-231; Muravchik, Joshua (2006): "How to Save the Neocons", Foreign Policy (Noviembre/diciembre 2006), p. 68; Murray (2006), op. cit., p. 208. Recientemente, John Bolton ha vuelto a afirmar la necesidad de cambiar radicalmente la política estadounidense hacia Irán y de llevar a cabo esta doble acción: un ataque preventivo de carácter selectivo realizado por los EE.UU. (o Israel) contra instalaciones clave del programa nuclear iraní y un apoyo decidido a la oposición para acabar con el régimen de los ayatolás; véase: Bolton, John R. (2015): "To Stop Iran's Bomb, Bomb Iran", The New York Times, 26 de marzo de 2015.

${ }^{71}$ Rubin, Jennifer (2013): "Who will stand up to Iran and against Obama's appeasement?", The Washington Post, 20 de noviembre de 2013.

72 Delreal, Jose (2013): "Charles Krauthammer: Worst Since Munich", Politico, 26 de noviembre de 2013, en http://www.politico.com/story/2013/11/charles-krauthammer-obama-munich-100383.html;

Bolton (2015), op. cit.
} 


\section{La debilidad militar y la reticencia a emplear el poder americano}

Como ya sabemos, el neoconservadurismo ha hecho de la superioridad militar uno de sus dogmas y componentes esenciales de su visión excepcionalista de los EE.UU. Según los neoconservadores, es imprescindible que los EE.UU. mantengan un nivel de gasto militar que permita afrontar a la superpotencia las cargas que le corresponden como hegemón ${ }^{73}$. Por ello, es lógico que el aumento constante del gasto militar haya sido una exigencia permanente y prioritaria en el discurso neoconservador durante la Guerra y Fría y también tras ella, a pesar de haber desaparecido el enfrentamiento bipolar y el principal enemigo de los EE.UU. ${ }^{74}$. Así, afirman que es preciso acabar con los recortes del gasto militar pues, a su juicio, el coste de la primacía mundial americana no es prohibitivo, mientras que los costes de reducir el papel de los EE.UU. en el mundo son, en cambio, incuantificables ${ }^{75}$. La importancia que los neoconservadores conceden a la primacía militar es tal que, como ha afirmado Robert Kagan, el aspecto más preocupante del legado de Obama una vez que termine su mandato será el de la merma del poder americano como resultado de la reducción del gasto militar ${ }^{76}$.

La debilidad militar que denuncian los neoconservadores no se limita sólo a aspectos materiales, sino que alude también de manera crucial a aspectos volitivos. Si los recortes del gasto militar son graves no menos lo es la falta de voluntad política de usar el poder militar americano de la que, desde su punto de vista, ha hecho gala el presidente Obama. En este sentido, se puede decir que para los neoconservadores la debilidad militar entendida en términos materiales es consecuencia de la debilidad moral. En este sentido, los recortes en el gasto militar no son sino el corolario de la renuncia a emplear el poder americano en la defensa de los intereses y valores de los EE.UU. Tras esta falta de voluntad en el uso de la fuerza, se encuentra la ausencia de creencia en los valores propios: no se considera que estos sean superiores ni universales, y por ende no se siente la necesidad de defenderlos frente a otros valores que se consideran igualmente legítimos. En último análisis, esta cuestión alude a la propia concepción de los EE.UU. de Barack Obama, esto es, a su modelo político y social $^{77}$.

En opinión de los neoconservadores, la debilidad militar de la política exterior de Obama se ha revelado de forma manifiesta en diversos ámbitos de la misma. Así, dicha debilidad ha sido explotada por Rusia, a la que los EE.UU. han hecho concesiones unilaterales que, lejos de mejorar la relación bilateral con Moscú, han facilitado su política de poder como gran potencia. La política de apaciguamiento de Obama ha sido respondida por Putin con la anexión de Crimea y la injerencia permanente en Ucrania $^{78}$. Otro ejemplo significativo sería el caso de Siria, donde Obama incumplió su propia amenaza de usar la fuerza contra el régimen de Al-Asad si éste transgredía la 'línea roja' de emplear armas químicas y no ha

\footnotetext{
${ }^{73}$ En este sentido, los neoconservadores defienden que el Gobierno federal americano reduzca el gasto en programas sociales, para concentrar la inversión pública en prioridades de seguridad nacional; véase, Quinn, op. cit., pp. 807-808.

${ }^{74}$ Murray, op. cit., p. 62.

${ }^{75}$ Ibid., pp. 128-130..

${ }^{76}$ Kagan, Robert y Zakaria, Fareed (2014): "The Munk Debate: Obama's foreign policy", The Foreign Policy Initiative, November 5, en http://www.foreignpolicyi.org/content/munk-debate-obama\%E2\%80\%99s-foreignpolicy.

${ }_{77}$ Así, según Krauthammer, la actual política exterior de americana está íntimamente ligada a la política interna: Obama pretende llevar a los EE.UU. hacia el modelo socialdemócrata europeo aumentando el gasto público en políticas sociales a costa de reducir el presupuesto militar y el protagonismo americano en los asuntos internacionales; véase: Krauthammer (2009), op. cit., p. 4.

${ }^{78}$ Véanse: Boot, Max (2014): "U.S. Ukraine Policy: Dumb and Immoral", Commentary, 10 de septiembre de 2014, en https://www.commentarymagazine.com/2014/09/10/u-s-ukraine-policy-dumb-and-immoral/; Boot, Max (2014): "The Inevitable Appeasement of Vladimir Putin", Commentary, 3 de septiembre de 2014, en http://www.commentarymagazine.com/2014/09/03/the-inevitable-appeasement-of-putin/.
} 
prestado la asistencia militar adecuada a la insurgencia ${ }^{79}$. Obama estaría usando, igualmente, con reticencia e insuficiencia la fuerza contra el avance del Estado Islámico en Irak y Siria. Para los neoconservadores, en ambos casos, el presidente americano ha hecho demasiado poco y cuando se ha decidido a actuar ha sido demasiado tarde (too little, too late ${ }^{80}$.

\section{Gobernanza global versus soberanía democrática americana}

Como consecuencia directa de su particular versión del excepcionalismo americano, la doctrina neoconservadora ha mantenido una inveterada tradición unilateralista que en la pasada década vivió su cénit durante el primer mandato de George W. Bush. El unilateralismo neoconservador se ha manifestado históricamente en un rechazo radical al concepto teórico y práctico de gobierno mundial (world government) ${ }^{81}$. Por lo tanto, no debe sorprender que la doctrina neoconservadora abomine también de la noción de gobernanza global (global governance), que, a su entender, no vendría a ser sino un calco de esa idea de gobierno mundial $^{82}$. La creación en abril de 2008 por parte del American Enterprise Institute del Observatorio sobre la Gobernanza Global (Global Governance Watch), es una clara evidencia de la gran preocupación que actualmente suscita esta cuestión en las filas neoconservadoras ${ }^{83}$ que la llegada al poder de Barack Obama no ha hecho sino acentuar. Para los neoconservadores Obama es el símbolo del multilateralismo y de la gobernanza global, es un presidente que trata de diluir la hegemonía americana en una panoplia de instituciones y normas internacionales ${ }^{84}$. En este sentido, han acusado al presidente de los EE.UU. de hacer del Consejo de Seguridad el eje de su política de seguridad y de conceder legitimidad a la Corte Penal Internacional (CPI) ${ }^{85}$, en claro contraste con la hostilidad de la Administración Bush hacia ambas instituciones.

En los últimos años, los neoconservadores han articulado un acerbo discurso contra la gobernanza global tanto en su dimensión conceptual como institucional. Consideran que los partidarios de la gobernanza global, los llamados 'globalistas' o 'transnacionalistas', persiguen extender a todo el mundo un 'imperio de la ley global' (global rule of law) inspirado en el modelo supranacional de la Unión Europea, con la finalidad de controlar y limitar el poder de los EE.UU. ${ }^{86}$. En efecto, para los neoconservadores la gobernanza global, vertebrada a través de instituciones multilaterales como la CPI y el sistema de seguridad colectiva de la ONU, constituye un ataque contra la soberanía americana y un intento de cercenar la política exterior de los EE.UU. ${ }^{87}$. De igual modo, la misma representa una amenaza contra la democracia americana, ya que a través de sus instrumentos pretende

\footnotetext{
${ }^{79}$ Wehner, Peter (2013): "Obama's Syria Debacle Inflicts Historic Damage on America", Commentary, 10 de septiembre de 2013, en http://www.commentarymagazine.com/2013/09/10/obamas-syria-debacle-inflictshistoric-damage-on-america/.

80 "Krauthammer's Take: Obama 'Too Little, Too Late' on ISIS — 'As Usual', National Review Online, August 11, 2014, en http://www.nationalreview.com/corner/385199/krauthammers-take-obama-too-little-toolate-isis-usual-nro-staff.

${ }^{81}$ Así, según Irving Kristol, este debe ser rechazado porque conduce a la tiranía: Kristol (2003), op. cit., p. 36.

${ }^{82}$ En este sentido: Fonte, John (2011a): Sovereignty or Submission: Will Americans Rule Themselves or be Ruled by Others?, New York, Encounter Books, pp. 11-15. Bolton, John R. (2012): "Against the globalistas", Claremont Review of Books, vol. 12, no 2 (Primavera 2012), p. 55.

${ }^{83}$ Drolet, Jean-François (2011): American Neoconservatism: the Politics and Culture of a Reactionary Idealism, London, Hurst \& Co., p. 161.

${ }^{84}$ Krauthammer (2009), op. cit., p. 2.

${ }^{85}$ Bolton, John (2011): "A United Nations Court For Gadhafi?", The Wall Street Journal, 1 de marzo de 2011, en http://online.wsj.com/articles/SB10001424052748704615504576172333428911782.

${ }^{86}$ Véase: Fonte (2011a), op. cit., p. 157 y 158.

${ }^{87}$ Bolton (2012), op. cit., p. 56.
} 
someter a los EE.UU. a principios, normas y procedimientos que no han sido aprobados por sus instituciones democráticas ${ }^{88}$. Por ende, la gobernanza global no sólo diluiría el poder americano en un entramado de instituciones y normas internacionales sino que debilitaría su soberanía democrática. Así, los neoconservadores entienden que la gobernanza y la soberanía democrática americana son conceptos antagónicos y excluyentes, de modo que los líderes estadounidenses deben elegir bien entre la soberanía que encarna la democracia liberal o la sumisión que encarna la gobernanza global ${ }^{89}$.

Así, la cuestión de la gobernanza global plantea un desafío fundamental, 'existencial' según Fonte, sobre la democracia americana en la actualidad y en los próximos años: una batalla política e ideológica entre 'globalistas' -entre los que a su juicio se halla sin duda Barack Obama - y 'soberanistas' —entre los que se encuentran destacadamente los neoconservadores - que será decisiva para el futuro democracia liberal ${ }^{90}$. Frente a los globalistas, los soberanistas deben reafirmar el derecho de los estadounidenses a ser gobernados por sí mismos y no por instituciones internacionales carentes de legitimidad y control democráticos ${ }^{91}$.

Para los neoconservadores la conclusión es clara: los EE.UU., en tanto hegemón del sistema internacional, y bajo la guía de líderes que crean en la primacía de la soberanía democrática americana, pueden y deben frenar los intentos de avanzar en el desarrollo de la

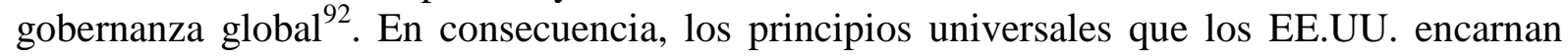
sólo pueden ser protegidos y difundidos en el mundo mediante la propia acción americana y de sus aliados democráticos, no a través de una gobernanza global ejercida por una serie de instituciones multilaterales carentes de legitimidad ${ }^{93}$.

\section{Conclusión: la auto-reivindicación del neoconservadurismo como (la mejor) doctrina de política exterior para los EE.UU.}

La polarización ideológica que ha caracterizado a la política americana en estos últimos tiempos ha alcanzado también a la política exterior. Si en el ámbito de la domestic policy el Tea Party ha sido el sector conservador más intransigente con las políticas sociales de Obama, en materia de política exterior los neoconservadores se han constituido en sus críticos más radicales. Para estos, como consecuencia de su negación del excepcionalismo americano, Obama ha implementado una política exterior que carece de los elementos fundamentales para garantizar la pervivencia del orden mundial americano: la superioridad militar y la claridad moral. La política exterior de Obama es, por ende, el paradigma de la amoralidad y de la debilidad, y conduce inexorablemente al declive de los EE.UU. en el escenario internacional.

El discurso neoconservador durante el 'sexenio Obama' pretende reivindicar la validez y vigencia de una doctrina de política exterior sometida a enormes críticas tras la guerra de

\footnotetext{
${ }^{88}$ Fonte, John (2011b): "Sovereignty or Submission: Liberal Democracy or Global Governance?", Foreign Policy Research Institute, November, pp. 2-4. CEASER, James W.: "Are we ready for rule by "the party of global governance'?", The Weekly Standard, vol. 17, no 18, 23 de enero de 2012, en http://www.weeklystandard.com/articles/one-world_616714.html?page=1.

${ }^{89}$ Fonte (2011b), op. cit., pp. 4 y 5.

${ }^{90}$ Fonte, John (2008): "Global Governance vs. the Liberal Democratic Nation-State: What Is the Best Regime?", Hudson Institute, 2008 Bradley Symposium, Washington, DC, 4 de junio de 2008, pp. 17-18, en http://archive.frontpagemag.com/readArticle.aspx?ARTID=31179.

${ }^{91}$ En este sentido, véase, Ibid., pp. 15 y 16.

${ }^{92}$ Ibid., pp. 17 y 18.

${ }^{93}$ Fonte (2011b), op. cit., p. 4.
} 
Irak de 2003. El neoconservadurismo se sigue ofreciendo a sí mismo como la mejor alternativa a las principales escuelas americanas: la realista y la liberal ${ }^{94}$. Frente a la amoralidad del realismo, el neoconservadurismo sigue alzando la bandera de los principios morales como elemento rector fundamental de la política exterior. De igual modo, la centralidad que el neoconservadurismo concede a la democracia en las relaciones internacionales sigue siendo una diferencia fundamental respecto del realismo. Frente a la apuesta del internacionalismo liberal por las instituciones y el Derecho internacional para avanzar en la construcción de la gobernanza global, los neoconservadores propugnan la defensa de la soberanía nacional americana como el único instrumento adecuado para garantizar la seguridad de los EE.UU. y la pervivencia de sus valores democráticos.

En todo caso, y en contra de quienes defienden, tanto desde el realismo como desde el liberalismo americano, la 'normalidad' estadounidense y el fin del excepcionalismo, los neoconservadores nunca renunciarán a considerar que los EE.UU. son una nación excepcional con una misión que cumplir en el mundo. Asimismo, el neoconservadurismo sigue combatiendo toda tentación de repliegue y retirada del mundo, en el entendido de que toda inclinación aislacionista implica un grave peligro para la seguridad de los EE.UU. y la seguridad internacional. Los EE.UU. deben volver a asumir la carga de responsabilidad que comporta mantener el orden mundial nacido hace casi setenta años, asumiendo que su activismo global es indispensable para tal cometido.

Si bien es cierto que desde la llegada al poder de Obama la influencia política del neoconservadurismo es prácticamente inexistente, no hay que desconocer su dinamismo demográfico, institucional e intelectual sigue siendo digno de tener en cuenta ${ }^{95}$. De hecho, el movimiento sigue contando con un sólido grupo de partidarios dispuestos a defender la superioridad de sus ideas pese a los errores cometidos. Asimismo, hay que señalar que las organizaciones neoconservadoras no han perdido la vitalidad y el activismo que las ha caracterizado siempre ${ }^{96}$. En cuanto al dinamismo intelectual, hay que reiterar que el neoconservadurismo sigue ocupando un espacio propio en el marco de las doctrinas de política exterior estadounidense y que cuenta, asimismo, con el activo de poseer un discurso fuertemente arraigado en la cultura política americana ${ }^{97}$.

Un ejemplo claro del persistente dinamismo de los neoconservadores lo hallamos en su papel en las dos últimas elecciones presidenciales, en las que, pese al desprestigio generado por la guerra de Irak, lograron posicionarse bien dentro de las candidaturas republicanas. En efecto, tanto John McCain en 2008 como Mitt Romney en 2012 incluyeron en sus equipos a varios asesores neoconservadores, en un significativo equilibrio con los realistas. Ello reflejaría la buena posición que mantienen los neoconservadores en el seno del Partido

\footnotetext{
${ }^{94}$ Muravchik (2010a), op. cit., p. 16.

${ }^{95}$ Vaïsse, Justin (2010): "Why Neoconservatism Still Matters", Brookings Institution, Policy Paper, no 20, (mayo de 2010), pp. 7-10, en

http://www.brookings.edu/ /media/research/files/papers/2010/4/05\%20neoconservatism\%20vaisse/05_neoconse rvatism_vaisse.pdf.

${ }^{96}$ El cese de actividad del emblemático think tank neoconservador PNAC en 2006 se vio pronto suplido por la creación de la Foreign Policy Initiative (FPI) en 2008, liderada por Robert Kagan y William Kristol, que ha continuado criticando la política exterior de Obama y ofreciendo una alternativa a la misma. Asimismo, la presencia neoconservadora sigue siendo importante en think tanks como el American Enterprise Institute o el Hudson Institute, e incluso hay que señalar la creación de dos centros que habría que situar en la órbita neoconservadora: el George W. Bush Institute (2008), en Texas, y la Henry Jackson Society (2005), en Londres.

${ }^{97}$ En este sentido, véase: Schmidt, Brian C. y Williams, Michael C.: "The Bush Doctrine and the Iraq War: Neoconservatives Versus Realists", Security Studies, vol. 17, nº 2 (2008), pp. 219 y 220.
} 
Republicano y mostraría, a su vez, de la contienda ideológica que en el mismo existe entre ambas corrientes $^{98}$.

Para los neoconservadores, el mayor desafío que afrontan actualmente los EE.UU. es tratar de revertir el declive estadounidense en el escenario mundial, propiciado, a su juicio, por la política exterior 'declinista' desarrollada por la Administración Obama. Considerando que uno de los presupuestos esenciales para que los neoconservadores ejerzan un grado de influencia relevante en la política exterior estadounidense es lograr que un republicano llegue de nuevo a la Casa Blanca, es indudable que el principal objetivo neoconservador es contribuir a lograr una victoria del Grand Old Party en las próximas elecciones presidenciales de 2016. En este sentido, los neoconservadores tratarán de lograr posiciones relevantes en las candidaturas del Partido Republicano para que sus ideas sigan siendo la alternativa a las posiciones realistas.

\footnotetext{
${ }^{98}$ En este sentido, véase: Singh, Robert (2014): "Neoconservatism in the age of Obama" en Parmar, Inderjeet et al. (eds.): Obama and the World: New directions in US foreign policy, $2^{\text {nd }}$ edition, New York, Routledge, pp. 37 y 38 .
} 